* Corresponding author E-mail address:domnita.fratila@tcm.utcluj.ro (Assoc. prof. Dr. Eng. Domnita Fratila)

Article information

Article history: AMS-Volume16-No.1-00143-12 Received 4 December 2011 Accepted 15 January 2012

\section{Research of Environment-Friendly Techniques Influence on Accuracy of Gear Processing in Context of Sustainable Machining by Near Dry Machining}

\author{
Domnita-Florina Fratila
}

Technical University of Cluj-Napoca. Machine Building Faculty, Department of Manufacturing Engineering, Bd Muncii 103-105, 400641 Cluj-Napoca, Romania

\section{BIOGRAPHICAL NOTES}

Domnita Fratila, Assoc.prof. Dr. Eng. is an associated professor at the Technical University of Cluj-Napoca, Machine Building Faculty, Department of Manufacturing Engineering, Romania. She graduated at the Technical University of Cluj-Napoca, Machine Building Faculty, in 1996. Her professional orientation is focused on the manufacturing technologies, environment friendly techniques, eco-design, as well as micro-fabrication and micro-assembly. She is a member of the "Young Researches' and Scientists' Committee" in the framework of the "DAAAM International Association" and also member of the "Academic Association for Manufacturing Engineering."

\section{KEY WORDS}

Milling, gear accuracy, near-dry machining, sustainable machining

\section{ABSTRACT}

This paper highlights the importance of the sustainable machining technologies in achieving sustainable development objectives. The machining processes constitute a major manufacturing activity that contributes to the growth of the global economy. The research and the development in the machining processes have improved machining performances through advanced tool materials, higher productivity and quality, while the environmentally and the health-friendly technologies are becoming increasingly important for achieving cleaner, healthier, and safer machining. In the context of the sustainable machining, the case study presents the influence of the environment-friendly techniques use on the accuracy of $16 \mathrm{MnCr} 5$ gear with small modulus, manufactured by milling.

\section{Introduction}

The new concept of sustainable production concerns on the creation of products and services, using the non-polluting processes and systems, besides conserving the natural resources and the energy. Such model should be economically viable, safe and healthful for the employees and attractive for the consumers and the communities [18].

The metal machining companies are currently under increasing pressure of the competition, the environmental regulation, and the supply chain demanded for improved environmental performance [19], [31]. The conventional production knowledge has 
three levels, consisting on: the idea (the design of new products), CAD (Computer Aided Design) and CAM (Computer Aided Manufacturing). As an alternative, the sustainable production put all these components on the same level defining the sustainable product based on the sustainable principles.

In the machine building industry, several oils/ emulsions are still used as cutting fluids, causing through their use the environmental pollution and health hazards. Additionally to the high costs involved, they are one of the most important health hazards in the workplace [27], [28]. The machining industry investigates the methods in order to increase the process performance and to reduce the production costs, in addition to the growing environmental concerns [1], [2].

These fundamental issues are possible to be solved by sustainable product design and manufacturing. The sustainability of a product and/or production can be achieved with the improvements on all levels: the economy design (the real market demand correlated with the costs and the quality), the resources utilization (the improvement of the proportion between the incoming and the outgoing raw materials in the production stage, what basically represents wastes). With the implementation of the sustainability principles in the machining processes, the companies have the potential to save costs and to improve their environmental performance even the production stays on the same size or it is decreased [3], [9].

The way to achieve the sustainable development is the adoption, by a long term strategy, of the sustainable manufacturing practices like [11], [15]:

- Improved environmental, health and safety performance;

- Improve working conditions;

- Use resources (materials, water, energy) with high efficiency;

-Minimize waste (less waste generated and increase waste recycling or re-usage);

- Adopt sustainable engineering techniques;

- Avoid/ improve the management of metal working fluids, lubricants and hydraulic oils;

- Training the employees about sustainable practices.

Concerning the machining processes and the application of the sustainability principles, the measures have to be defined for the level determination of the machining process sustainability [11], [16], [21]. Usually the process evaluation measures are:

- Quality of the machined product through surfaces integrity;

- Costs of the machining process and their potential reductions;

- Resources and energy consumption;

- Waste production and their disposal costs;

- Environmental performance;

- Health and safety performance;

- Competitiveness, skill level and public image.

The overall part production process consists of the machining, the cooling/ lubrication, the part cleaning, the preparation of chips to be disposed and their interactions [19], [20], [21], [22]. In the conventional machining the cutting fluids are needed (cooling lubrication fluids-CLF or cleaning emulsion-CE). Compared to the conventional cooling methods, the environment-friendly techniques have some potential benefits like:

- Sustainable machining through the lower flow rates of CLF, providing better cooling and lubrication mechanisms;

- Decrease of the cutting tool-chip contact length, resulting in the lower cutting forces and the lower tool wear;

- Extension of the machining parameters operational range, resulting in the increased process productivity.

The use of dry cutting and near dry machining could offer the possibility for efficiency increasing, stemming from the lubricants elimination in the form of conditioned waste, the process chain optimization, as well as the improvement of the operational environment. The study performed and presented in this paper try to analyze if the ecological friendly techniques can be implemented to the milling process of the gear with small modulus. The procedure is strongly dependent on the concrete process characteristics, the material properties of work piece and tool.

\section{Sustainable Machining Process by Near-dry Machining (NDM)}

The pressure of the environmental awareness has led to a critical consideration of the conventional cooling lubricants usage in the machining processes. The studies carried out on this issue showed that the manufacturing costs related to the cutting fluids are in a range from $10-17 \%$ of the 
total costs and the tooling costs can account for approximately 2-4\% [10], [13], [14], [30]. Thus, the use of NDM can lead to a significant cost reduction. The key issue for the sustainable machining process is to analyze and understand the machining process and how the cooling and lubricating mechanisms dealt with.

Generally, in the cutting processes are used emulsions (oil-water mixture) or oils, depending on: the manufacturing operation, the machining tasks, the cutting tool materials, and the work piece materials [4], [5]. In the practice it is not always possible to reach the goal of cutting fluids usage reduction by simple turn off the cooling/lubricating supply [8], [9], [12], [15]. The reason lies in the cutting fluids tasks like: the reduction of the temperature in the cutting zone, the reduction of the friction and the transport/ evacuation of the chips, the cleaning of the tools, the work piece and the fixture. In the case of the cutting fluids absence, these tasks have to be taken by over by other components in the machining process [3], [8], [17], [29].

Table 1: Comparison of cutting fluids effects.

\begin{tabular}{|l|l|l|l|}
\hline Medium & \multicolumn{1}{l}{$\begin{array}{l}\text { Cooling } \\
\text { effect }\end{array}$} & \multicolumn{1}{l|}{$\begin{array}{l}\text { Lubrication } \\
\text { effect }\end{array}$} & \multicolumn{1}{l|}{$\begin{array}{l}\text { Chip } \\
\text { removal }\end{array}$} \\
\hline Eulsion & excellent & good & excellent \\
\hline Oil & good & excellent & good \\
\hline Compressed Air & low & no & low \\
\hline
\end{tabular}

The comparison of three different fluids characteristics are presented in Table 1. The oils are preferred when the good lubrication properties are needed, to reduce the friction and the adhesion between the chip-tool and the tool-work piece interface.

Using emulsion or pure water in NDM is less frequent, that choice been used when the cooling is needed to improving the process efficiency [7], [22], [23], [24], [25], [26]. Most of the benefits of the conventional cutting fluids in the machining are decreased by using of pure compressed air. The main reasons for different characteristics of the cutting media are the thermal capacity and the flow rate.

In the minimum quantity lubrication (MQL), the media feeded to the cutting area in small quantities (10-20 ml/hour) is generally the oil, but in some application the emulsion and the water are used. Thus, MQL or NDM is the use of a minimal amount of cutting fluid mixed with air as an aerosol in order to provide the controlled lubrication and to reduce the friction at the cutting-edge zone [17].

The transportation medium is usually the air or the droplets are formed and feeded to the cutting zone in the way of aerosol spray (in the case of the airless system).

Although some MQL-technology suppliers claim that any cutting fluid can be used with this technique, the most customers use the vegetable oil highly refined or the ester oil. These high-performance oils have excellent lubricity and natural dissolving properties, and they are environmentally friendly [28], [30]. With the increasing trends in the achieving sustainable machining, the dry and near-dry techniques are emerging as viable and more sustainable alternatives to the flood cooling in the machining processes.

\section{Experimental Setup and Procedure}

The research presented in this paper is a part of a wide research work done in the field of NDM implementation to gear milling and its consequences [4], [6], [31]. The factors influencing the gear processing precision are represented in Fig. 1.

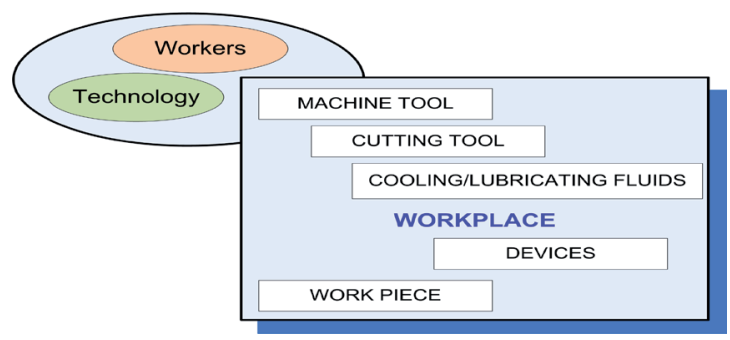

Fig. 1: Factors of influence on gear precision.

Based on these main factors it could be done a classification of the disturbances that are dependent of the process (Fig. 2).

\subsection{Influence of temperature variations on the gear ac- curacy}

The machine tools temperature is considered equal to the ambient temperature $\left(20^{\circ} \mathrm{C}\right)$. The increased temperature in the work piece during the processing, leads to the production of undesirable deformation whose magnitude should be considered.

It has been shown in practice that a metal with a length of $1 \mathrm{~m}$ changes its size by about $0.011 \mathrm{~mm}$ by increasing temperature with $1^{\circ} \mathrm{C}$. This value cor- 
responds to a diameter increase of $0.0012 \mathrm{~mm} /{ }^{\circ} \mathrm{C}$ (in the case of gear wheels with external diameter of $110 \mathrm{~mm}$ ). The experimental tests on the material behavior by the heating and cooling to the well defined temperatures (the measurement being made with the contact thermometer), show that the diameter changes are up to $0.00139 \mathrm{~mm} /{ }^{\circ} \mathrm{C}$.

Besides the measuring of the external diameter of the gear wheel, the spam change over 6 teeth has been checked. Thus, it was found that the amount of such size changes by $0.0078 \mathrm{~mm}$ to increase of the temperature with $1^{\circ} \mathrm{C}$. The research conducted shows that in the case of near-dry gear milling, the angular deviations of the flank lines are oriented towards the positive limit of the tolerance field. In order to avoid exceeding the allowable tolerance, it has been done the correction angle of the teeth (Fig. 3).

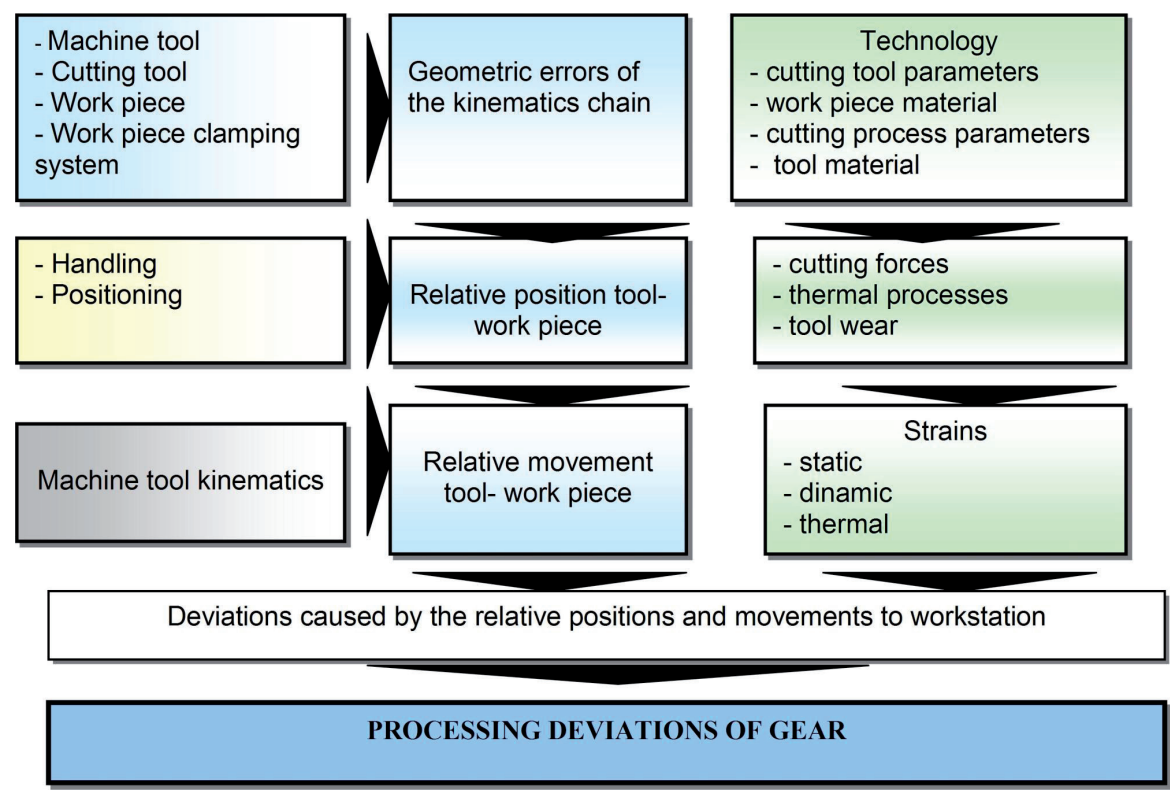

Fig. 2: Classification of the disturbances dependent of the process.

The inverse calculation of the angle correction is based on the following equations:

$\operatorname{tg} \beta=\frac{U}{L_{\beta}} \Rightarrow U=\operatorname{tg} \beta \cdot L_{\beta}$

$\operatorname{tg} \beta=\frac{U}{L_{\beta}} \Rightarrow U=\operatorname{tg} \beta \cdot L_{\beta}$

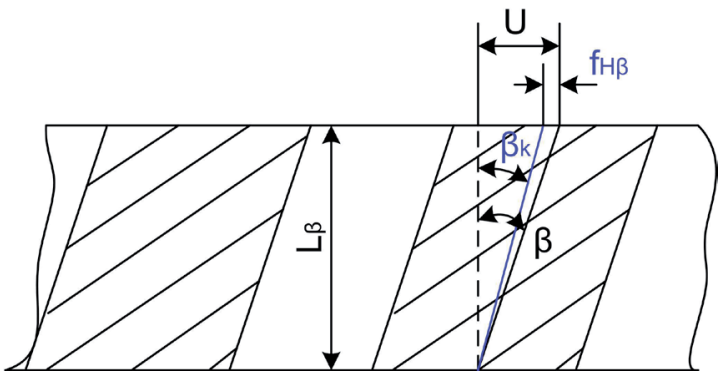

$U-f_{H \beta}=\operatorname{tg} \beta_{k} \cdot L_{\beta}$

where: $\beta$ - tooth inclination (tilt) angle, $\beta_{\mathrm{k}}$ - tooth inclination (tilt) angle corrected, $L_{\beta}$ - tooth width, $f_{H \beta}$ - tooth steering deviation, $U$ - flank lines tilt.

By the calculation of the angular deviations of the flank lines, the influence of the tooth tilt angle change has been determined. By using the equations (1)-(3) were obtained the angular deviations of the flank lines, which are used to calculate the theoretical deviations (Table 2 ).

Fig. 3: Tooth tilt angle correction.

Table 2: Teeth steering deviation.

\begin{tabular}{|l|l|}
\hline $\begin{array}{l}\text { Modification of tooth inclinati- } \\
\text { on (tilt) angle } \Delta \beta\left[^{\prime}\right]\end{array}$ & $\begin{array}{l}\text { Angular deviations of flank lines } \\
f_{\mathrm{H} \beta}[\mathrm{mm}]\end{array}$ \\
\hline 2 & 0,00896 \\
\hline 1 & 0,00448 \\
\hline 0,5 & 0,00224 \\
\hline
\end{tabular}




\subsection{Measurement of gear accuracy}

The performed experiments are focused on the technical evaluations of the cooling and lubrication effects, the cutting force behavior and the tool wear, while also emphasizing the effect of the above mentioned parameters on the process quality by the mean of the surface quality and the pollutant emissions concentration.

By using the five cooling and lubrication techniques (flood lubrication, dry cutting, minimal quantity lubrication, minimal cooling technique - MCT, minimal quantity cooling and lubrication $-M Q C L), 300$ gears are manufactured by milling (60 to every cooling lubrication method). The following media have been used as cutting fluids: ROTANOR oil (fluid flow - $100 \mathrm{l} / \mathrm{min}$ ) for $\mathrm{FL}$, vegetal oil (fluid flow - $0.4 \mathrm{ml} / \mathrm{min}$ ) for $\mathrm{MQL}$, emulsion with anticorrosion additives (fluid flow $-25 \mathrm{ml} / \mathrm{min}$ ) for $M C T$, vegetal oil (fluid flow $-0.4 \mathrm{ml} / \mathrm{min}$ ) and compressed air (5 bar) for MQCL.

The work pieces were made of $16 \mathrm{MnCr} 5$ with hardness between 55-60 HRC, their external diameter being de $=110 \mathrm{~mm}$. The experiments were carried out on a rigid CNC milling machine PFAUTER PE 500 CC220. The main cutting parameters are cutting speed $-130 \mathrm{~m} / \mathrm{min}$ and axial feed -2.7 $\mathrm{mm} /$ work piece rotation.

The manufactured gears have the following characteristics: material - $16 \mathrm{MnCr} 5$, normal module $-2.75 \mathrm{~mm}$, number of teeth -37 , root diameter $-103.82 \mathrm{~mm}$, face width $-19 \mathrm{~mm}$, teeth etch angle - 18050', gearing angle - 23045'. Gear parameters measurement was performed on a measurement coordinated multi-center HÖFLER EMZ 632 presented in Fig. 4.

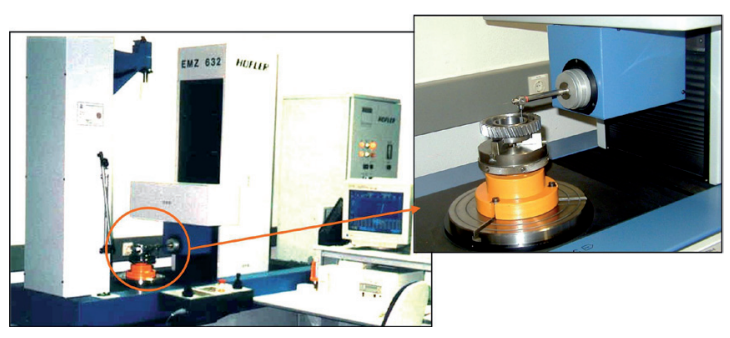

Fig. 4: Experimental setup

\section{Results and Discussions}

The research results highlight the influence of the cooling method, used during the milling process, on the gear wheel accuracy. In order to study the cooling lubrication technique on the gear accuracy, every second gear wheel machined has been measured.

The following charts represent and compare the values of some characteristics parameters measured according to DIN 3961-62, in order to evaluate the gear accuracy: the teeth thickness over pins (Md), the span measurements over 6 teeth (W6), the tooth thickness (s), total deviations of tooth profile $(\mathrm{Fa})$, total deviations of tooth flank lines (F $\beta)$ and unitary circular pith deviation (fp), in the cases of the five different cooling lubricating techniques mentioned above.

The admissible values, considered as basis for the wheels accuracy assessing, are those appropriate for the accuracy class $8: M_{d}=110,811 \mathrm{~mm}$, $W_{6}=45.670 \div 45.705 \mathrm{~mm}, \mathrm{~s}=3.673 \mathrm{~mm}, F_{a}=0 \div 20 \mu \mathrm{m}$, $F_{\beta}=0 \div 18 \mu \mathrm{m}, \mathrm{f}_{\mathrm{p}}=0 \div 14 \mu \mathrm{m}$. To determine the evolution of each parameter with increasing number of the processed gears, the trend of the variation was represented too (the continuous lines in the diagrams). The admitted ranges or values of each parameter are indicated in the diagrams (Fig. 5 to Fig. 10) by the dashed lines.

After processing 60 wheels, the variation analysis of the span measurement over 6 teeth reveals that the MQL allows obtaining a stable quality during processing comparable to that of the conventional cooling case. The next parameter measured is the teeth thickness over pins, the results being presented plotted in Fig. 5.

$\mathrm{FL}$ produces the best precision processing and the most stabile process. In terms of this criterion, for assessing the most favorable gears precision (excepting $\mathrm{FL}$ ) is the use $\mathrm{MQCL}$ and minimal lubrication technique (MCT), when the values of teeth thickness over pins are closed to the conventional cooling, the next favorable is the milling with the minimal lubrication.

The span measurement over 6 teeth $\left(W_{6}\right)$ exceeded allowable limits of tolerance field (44.699 : $44.705 \mathrm{~mm}$ - corresponding to the accuracy class 8 , represented in Fig. 6 with the dashed lines) after the dry processing of about 20 wheels. This means that the dry cutting (DC) is not favorable to the gear milling process with small module.

Figure 7 shows the tooth thickness values for the five considered cooling and lubrication techniques. In terms of the stability of this parameter during the processing of the parts batch, FL technique provides 
very good results. For other processes studied there is a similar tendency of the tooth thickness decreasing.

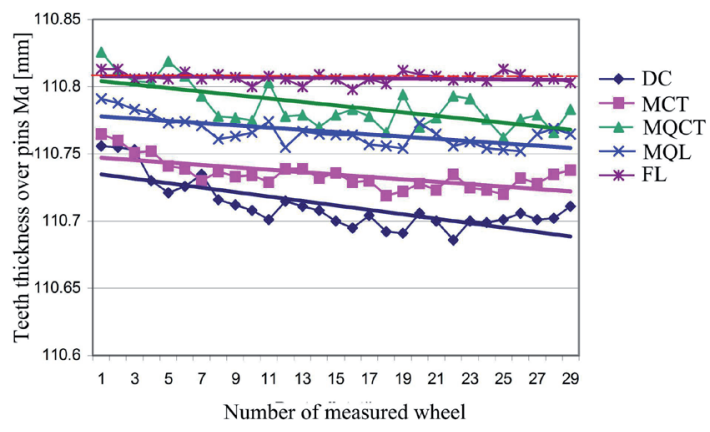

Fig. 5: Teeth thickness over pins $\left(M_{d}=110.811 \mathrm{~mm}\right)$.

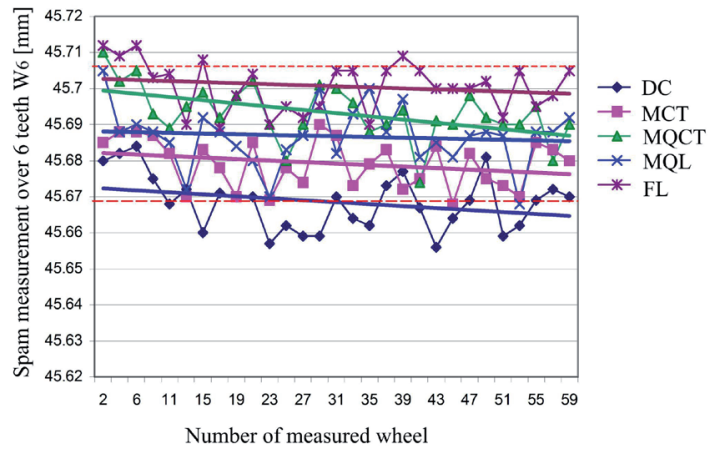

Fig. 6: Spam measurement over 6 teeth $\left(W_{6}=45.670 \div 45.705 \mathrm{~mm}\right)$.

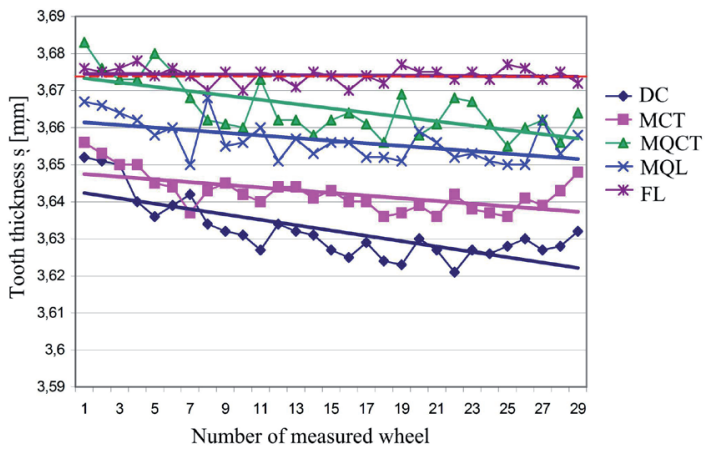

Fig. 7: Tooth thickness $(s=3.673 \mathrm{~mm})$.

Other deviations measured are: the deviation of tooth flank profile $F_{\alpha}$ the total deviations of tooth flank lines $F_{\beta}$ and the unitary circular pith deviation $f_{p}$. The results concerning these parameters are plotted in Fig. 8-10.

They indicate that for all variants of cutting process, the gear quality is similar to that obtained in the FL processing for the entire batch processed. That means that the errors are not a consequence of the cooling and lubrication failure due to use of the environment-friendly techniques.

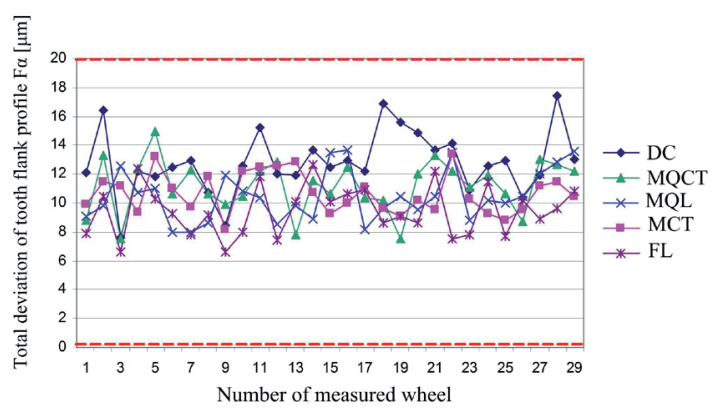

Fig. 8: Teeth thickness over pins $\left(M_{d}=110.811 \mathrm{~mm}\right)$.

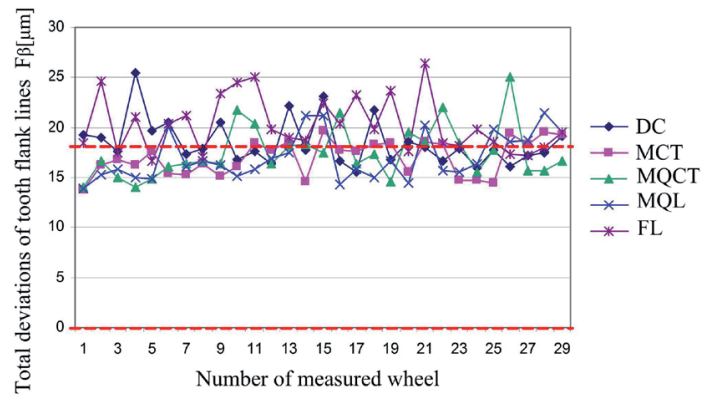

Fig. 9: Total deviations of tooth flank lines $\left(F_{\beta} 0-18 \mu \mathrm{m}\right)$.

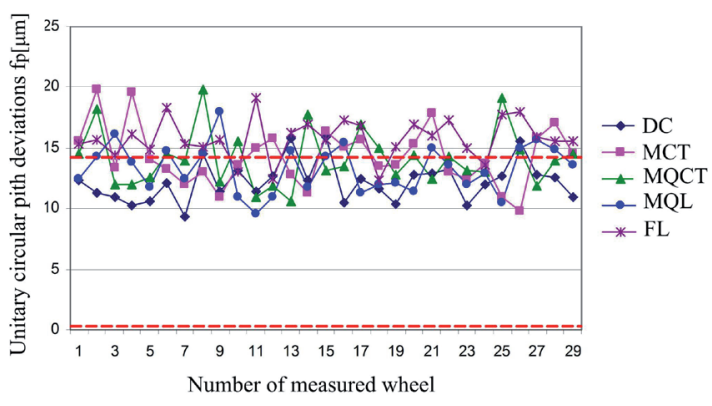

Fig. 10: Unitar circular pith deviation $\left(f_{p} 0-14\right)$.

\section{Conclusion}

The evaluation of the environment-friendly techniques was undertaken to understand the likely impacts of their use on the sustainability performance measures. The results are more than an experimental method for supporting the design of technology but also an instrument for supporting the decision- 
making in the case of the gear milling. This research supports technology policy and encourages the adoption and the application of the NDM in the industry.

The higher temperatures of the work piece and the tool to the gear milling using the minimal lubrication and cooling have not a negatively impact on the quality of the processed wheels. It could be concluded that the only parameter of the gear, whose accuracy is affected by the lubrication and the cooling rate is the tooth thickness. In terms of the gear quality assessing, the dry processing is not recommended if it uses the high speed steel tools with TiN coatings and the usual cutting parameters.

\section{Abrevuetions}

CAD - Computer Aided Design

CAM - Computer Aided Manufacture

CE - Cleaning emulsion

CLF - Cooling lubrication fluid

DC - Dry cutting

DIN - Deutsches Institut für Normung

$\mathrm{f}_{H \beta}-$ Tooth steering deviation

$\mathrm{FL}$ - Flood lubrication

$F_{\beta}$ - Total deviations of tooth flank lines

$F_{\alpha}$ - Deviation of tooth flank profile

$f_{p}-$ Unitar circular pith deviation

$L_{B}$ - Tooth width

$\mathrm{MQL}$ - Minimal quantity lubrication

MCT - Minimal cooling technique

$\mathrm{MQCL}$ - Minimal quantity cooling lubrication

$M_{d}-$ Teeth thickness over pins

NDM - Near-dry machining

$s$ - Tooth thickness

$U$ - Flank lines tilt

$W_{6}$ - Spam measurement over 6 teeth

$\beta$ - Tooth inclination (tilt) angle

$\beta_{k}$-Tooth inclination (tilt) angle corrected

\section{References}

[1] Byrne G., Dornfeld D., Denkena B., Advanced Cutting Technology, Annals of the CIRP, vol. 52, no. 2, 2003, p. 483-507.

[2] Byrne G., Scholta E., Environmentally Clean Machining Processes - A Strategic Approach, Annals of the CIRP, vol. 42, no. 1, 1993, p. 471-474.

[3] Dahmus I.B., Gutowski T.G., An environmental analysis of machining, Proceedings of IMECE, 2004, p. 1-10.

[4] El-Hossainy T.M., Tool Wear Monitoring under Dry and Wet Machining, Materials and Manufacturing Processes, vol. 16, no. 2, 2001, p. 165-176.
[4] El-Tamimi A.M., El-Hossainy T.M., Investigating the Tool Life, Cutting Force Components and Surface Roughness of AISI 302 Stainless Steel Materials under Oblique Machining, Materials and Manufacturing Processes, vol. 23, no. 4, 2008, p. 427-438.

[5] Fernández Pariente I., Guagliano M., Influence of Shot Peening Process on Contact Fatigue Behavior of Gears, Materials and Manufacturing Processes, vol. 24, no. 12, 2009, p. 14361441.

[6] Fratila D., Evaluation of near-dry machining effects on gear milling process efficiency, Journal of Cleaner Production, vol. 17, no. 9, 2009, p. 839-845.

[7] Ganesha Prasad M.S., Drakshayani D.N., Studies on Passive Cooling Techniques in Dry Machining, Materials and Manufacturing Processes, vol. 25, no. 6, 2010, p. 360-369.

[8] Graham I., Dom K., Going Dry, Manufacturing Engineering, 124(1), 2000, p. 72-78.

[9] Grzesik W., Dry and Semi-Dry Machining, Advanced Machining Processes of Metallic Materials, 2008, p. 226-245.

[10] Kaebernick H., Kara S., Sun M., Sustainable product development and manufacturing by considering environmental requirements, Robotics and Computer-Integrated Manufacturing, vol. 19, no. 6, 2003, p. 461- 468.

[11] Kalhofer E., Dry machining principles and applications. Proceedings of the 2 nd Seminario International de Alta Tecnologia UNIMEP. Julho, Brazil: Santa Barbara D'Oeste, SP, 1997.

[12] Kopac J., New achievements in cutting techniques, Journal of Mechanical Engineering, vol. 43, no. 34, 1997, p. 143-52.

[13] Kundrák J., Mamalis A.G., Gyáni K., Markopoulos A., Environmentally Friendly Precision Machining, Materials and Manufacturing Processes, vol. 21, no. 1, 2006, p. 29 - 37.

[14] Marksberry P.W., Jawahir I.S., A comprehensive tool-wear/ tool-life performance model in the evaluation of NDM for sustainable manufacturing, International Journal of Machine Tools and Manufacture vol. 48, no. 7-8, 2008, p. 878886.

[15] Marksberry P.W., Micro-flood (MF) technology for sustainable manufacturing operations that are coolant less and occupationally friendly, Journal of Cleaner Production, vol. 15, no. 10, 2007, p. 958-971.

[16] Paulo Davim J., Sreejith P.S., Silva J., Turning of Brasses Using Minimum Quantity of Lubricant (MQL) and Flooded Lubricant Conditions, Materials and Manufacturing Processes, vol. 22, no. 1, 2007, p. 45-50.

[16] Pusavec F., Krajnik P., Kopac J., Transition to sustainable production - Part I: application on machinig technologies, Journal of Cleaner Production, vol. 18, no. 2, 2010, p. 174184.

[17] Pusavec F., Kramar D., Krajnik P., Kopac J., Transitioning to sustainable production - part II: evaluation of sustainable 
machining technologies, Journal of Cleaner Production, vol. 18, no.12, 2010, p. 1211-1221.

[18] Rahman M., Kumar A.S., Salam M.U., Experimental evaluation on effect of minimal quantity lubricant in milling, International Journal of Machine Tools \& Manufacture, vol. 42, no. 1, 2002, p. 539-547.

[19] Rajemi M.F., Mativenga P.T., Aramcharoen A., Sustainable machining: selection of optimum turning conditions based on minimum energy considerations, Journal of Cleaner Production, vol. 18, no. 11-12, 2010, p. 1059-1065.

[20] Rama Kotaiah K., Srinivas J., Babu K.J., Srinivas K., Prediction of Optimal Cutting States during Inward Turning: An Experimental Approach, Materials and Manufacturing Processes, vol. 25, no. 6, 2010, 432-441.

[21] Ramesh S., Karunamoorthy L., Palanikumar K., Surface Roughness Analysis in Machining of Titanium Alloy, Materials and Manufacturing Processes, vol. 23, no. 2, 2008, p. 174181.

[22] Ramesh S., Karunamoorthy L., Palanikumar K., Fuzzy Modeling and Analysis of Machining Parameters in Machining Titanium Alloy, Materials and Manufacturing Processes, vol. 23, no. 4, 2008, p. 439-447

[23] Sayit E., Aslantas K., Çiçek A., Tool Wear Mechanism in Interrupted Cutting Conditions, Materials and Manufacturing Processes, vol. 24, no. 4, 2009, p. 476-483

[24] Shie J.R., Optimization of Dry Machining Parameters for
High-Purity Graphite in End- Milling Process by Artificial Neural Networks: A Case Study, Materials and Manufacturing Processes, vol. 21, no, 8, 2006, p. 838- 845.

[25] Sokovic M., Mijanovic K., Ecological aspects of cutting fluids and its influence on quantifiable parameters of the cutting process, Journal of Material Processing Technology no. 9, 2001, p. 181-189.

[26] Tan X.C., Liu F., A decision-making framework model of cutting fluids selection for green manufacturing, Journal of Material Processing Technologies, no. 129, 2002, p. 467-470.

[27] Tosun N., Huseyinoglu M., Effect of MQL on Surface Roughness in Milling of AA7075-T6, Materials and Manufacturing Processes, vol. 25, no. 8, 2010, p. 793-798.

[28] Weinert K., Inasaki I., Sutherland J.W., Wakabayashi T., Dry machining and minimum quantity lubrication, CIRP AnnalsManufacturing Technology, vol. 53, no. 2, 2002, p. 511-537.

[29] Westkämper E., Alting A., Life Cycle management and assessment: approaches and visions towards sustainable manufacturing (keynote paper), CIRP Annals - Manufacturing Technology, vol. 49, no. 2, 2000, p. 501-526.

[30] Pigosso D.C.A, Zanette T., Filho A.G., Ometto A.R., Rozenfeld

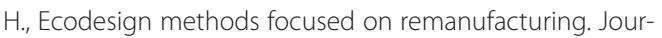
nal of Cleaner Production, vol. 18, no. 6, 2010, p. 21-31.

[31] Young P., Byrne G., Cotterel M., Manufacturing and Environment, International Journal of Advanced Manufacturing Technology, no. 13, 1997, p. 488-493. 